deaths in the inner north London coroner's district during the period 1971-85.

Six of the 10 underground stations with the highest frequency of incidents were situated within half a mile of a major psychiatric unit. The stations were King's Cross, Mile End, Tooting Bec, Oxford Circus, Hampstead, and Belsize Park.

\section{Discussion}

Railway suicides have been investigated in Canada, Denmark, the United States, and Britain, but the studies concentrated on fatal cases and their psychiatric features. ${ }^{8-11}$ Johnston et al examined the records of the Toronto subway and found that most incidents occurred between 1000 and 1700 hours. ${ }^{8}$ They recommended posting inspectors on the station platforms at peak hours. No similar clustering of incidents around peak times of day was found in the present study. Records were found for 19 survivors, and a high incidence of traumatic amputation was noted.

Lindekilde and Wang, in a study of railway suicide in Denmark, concluded that little more could be done by the railway authorities to prevent incidents and the problem would be better approached by preventive psychiatric treatment. ${ }^{9}$

Guggenheim and Weisman studied 50 cases from the Boston subway and found that most patients who attempted suicide were highly disturbed, with a similar high incidence of previous psychiatric illness. ${ }^{10}$ Symonds, investigating the psychiatric aspects of railway fatalities, noted 82 probable suicides in a group of 134 fatalities. ${ }^{11}$ In the present study the proportion was similar. Comparing the different studies shows that the percentage of patients who selected the railway as their method of suicide is similar (Denmark 3\%, Canada 7\%, inner north London coroner $6 \cdot 8 \%)$.

None of the above studies investigated survivors in detail. In the present study most of the patients survived. The only patients who died with an injury severity score of less than $\mathbf{4 0}$ were those with a single, severe injury - for example, a head injury — who were given a score of 25 . A study of long term morbidity and mortality has not yet been carried out, but it is known that four survivors have attempted suicide again during the study period. Three of these chose the underground train as their method, and one died. The fourth patient jumped from a high building and died. Other survivors have been noted to require repeated and prolonged admission to psychiatric units. The occurrence of five incidents concerning patients from a single ward in 1985 suggests that this method of suicide may be well known among groups of psychiatric patients.

It seems that in the time immediately after discharge from hospital the risk of suicide may be increased. Inpatients in psychiatric hospitals featured strongly in this study, and patients in the community often gave notice of their intentions. For these reasons some of the injuries and deaths may be considered to have been preventable.

I thank the British Transport Police for help in this study and Romana Yusufzai and Julie Rostron for help in preparing the manuscript.

\section{References}

1 London Transport daily diary of events 1916-1920. Archives, London Transport Museum, Wellington Street, London WC2.

2 Read CS. The problem of suicide. Br Med f 1936;i:631-4.

3 Anonymous. Subways and underground railways. In: Encyclopaedia Britannica. 15th ed. vol IX Cambridge: Cambridge University Press, 1984:637.

4 Anonymous. Information sheet. 1985. London Underground, 55 Broadway, London SW 1 H OBD 5 Baker SP, O'Neill B, Haddon W, Long WB. The injury severity score- a method for describing patients with multiple injuries and evaluating emergency care. $\mathcal{f}$ Trama 1974;14:187-96.

6 Steedman D, Robertson C. Who scores in trauma? Care of the Critically Ill 1987;3: May/June.

7 Chambers DR, Harvey JG. Data on methods selected in self-inficted death, 1971-1985. HM Coroner, Inner North London. Camley Street, London NW1 OPP.

8 Johnston DWC, Waddell JP. Death and injury patterns, Toronto subway system 1954-1980. f Trauma 1984;24:619-22.

9 Lindekilde K, Wang AG. Train suicide in the county of Fyn 1979-82. Acta Psychiatr Scand 1985;72:150-4.

10 Guggenheim FG, Weisman AD. Suicide in the subway. I Nero Ment Dis 1972;155:406-9.

11 Symonds RL. Psychiatric aspects of railway fatalities. Psychol Med 1985;15:609-21.

(Accepted 21 September 1987)

\title{
Effect of the 1983 Mental Health Act on the management of psychiatric patients
}

\author{
L WEBSTER, C DEAN, N KESSEL
}

\begin{abstract}
Two principal objectives of the 1983 Mental Health Act were to decrease the use of emergency orders and to give patients on observation orders the right of appeal. Statistics were collected from the 13 hospitals that admit acute psychiatric patients in the Greater Manchester area, and the figures for 1980-1 were compared with those for 1984-5. Changes in use of the different sections were examined in university units, large psychiatric hospitals, and district general hospital units. The use of emergency orders decreased and the use of treatment orders increased; the use of observation orders remained unchanged. Many more

\footnotetext{
Department of Psychiatry, University Hospital of South Manchester, West Didsbury, Manchester M20 8LR

L WEBSTER, MSC, MRCPSYCH, senior registrar

C DEAN, MD, MRCPSYCH, consultant

N KESSEL, FRCP, FRCPSYCH, professor

Correspondence to: Dr Webster.
}

patients exercised their right of appeal in 1984-5, but the number discharged by tribunals remained small. The nurses' holding power was used infrequently. The different types of hospital are now more concordant in their use of these orders than before the 1983 act.

\section{Introduction}

The 1983 Mental Health Act was intended to be a liberalising act, increasing rights of appeal for detained patients and discouraging the overuse of emergency orders. Some of the new provisions in the act were welcomed by all concerned with its use, but others aroused predictions of unworkability.

Section 2 of the act replaces section 25 as a 28 day order for assessment but contains additional powers to enforce treatment if necessary. A major addition to this section is the right of appeal to a mental health review tribunal within 14 days of admission. It was predicted that the threat of a tribunal before there was a chance to assess a patient properly would lead psychiatrists to avoid using 
section 2 wherever possible. ${ }^{1}$ The options would then polarise so that the patient would be admitted under either an inadequate 72 hour order without provision for enforcing treatment or an overrestrictive six month order.

There had been much criticism of the old section 29, the 72 hour emergency admission order. Its principal use in some places was to short circuit the geriatric waiting list, ${ }^{2}$ and in most places the number of emergency orders exceeded the number of observation orders, indicating that they were not being used in genuine emergencies. ${ }^{3}$ Over $60 \%$ of compulsory admissions in England and Wales made use of the emergency sections, contrary to the intention of the 1959 act. $^{4}$ The new act makes the criteria for using section 4 stricter in an attempt to confine its use to genuine emergencies. This might be expected to have led to a reduction in its use in hospitals where it had previously been commonly used.

Section 5.2 corresponds to the previous section 30 and allows detention for 72 hours of a patient already in hospital. The new law confines those who can sign this order to the consultant in charge or his nominated deputy. This safeguard might lead to less use of this power.

An entirely new section 5.4 allows nurses to detain a patient for up to six hours until a doctor eligible to sign a section 5.2 order arrives. It is important to evaluate how it is used and how often and whether such patients are subsequently detained or discharged.

Section 58 concerns consent to treatment and applies to detained patients receiving drug treatment lasting more than three months or electroconvulsive therapy, or both. Although this was not required by the 1959 act, the Royal College of Psychiatrists recommended that a second opinion should be sought if a patient refused electroconvulsive therapy. Section 58 , however, states that a second opinion must be obtained not only if the patient refuses but also if the patient agrees but is regarded as "incapable of understanding the nature, purpose and likely effects of the treatment." The doctor providing the second opinion is required to consult a nurse and another member of the clinical team, who must be neither a doctor nor a nurse. These requirements were condemned by some clinicians, who thought that they cast a slur on the doctors' competence and that bringing a multidisciplinary team into clinical decision making would be "frankly unethical." In defence of the new requirements it was stated that "the right of capacity to form an independent opinion is not forfeited as a result of consulting with another discipline or service." Some predicted that the sheer numbers of patients requiring a second opinion on the vague grounds of incapability would lead to administrative chaos and unacceptable delays in treatment. ${ }^{7}$

It was predicted that under the new act the number of tribunal hearings would rise from 904 in 1980 to about 4500 a year because of the new right of appeal under section 2 and automatic review of patients under section 3 (the treatment order) after six months. ${ }^{8}$ Doubts were expressed about how the new system would work in practice.

In a recent survey the views of 118 consultant psychiatrists about difficulties in implementing the 1983 act were sought within the first six months of its use. ' Questions were asked about the use of section 2 with the new tribunal rights, the consent to treatment provisions, the use of the nurses' holding power, and other changes. The majority response $(75-95 \%)$ on all issues was that no difficulties had by then risen, but some respondents anticipated problems. Information from 16 psychiatric hospitals about the numbers and types of compulsory detentions in a 12 month period before September 1983 and in the four months after that date showed a $60 \%$ reduction in admissions on emergency orders. 9

In an early report six months after the new act Winterson and Barraclough noted a reduction in the use of emergency orders in a district general hospital. ${ }^{10}$ In a more recent report they suggested that the change in practice is permanent and not just a transitory effect. ${ }^{11}$

\section{Methods}

The 13 hospitals receiving acute psychiatric admissions in the old administrative area of Greater Manchester provided access to their records.
TABLE I-Total numbers of each section used in 1980-1 and 1984-5

$\left.\left.\begin{array}{lccrc}\hline \text { Year } & \text { Section No } & \text { No of discharges } & \text { No }(\%) \text { of sections } & \chi^{2} \\ \hline 1980-1 & 25 & 20677 & 1399(6 \cdot 7) \\ 1984-5 & 2 & 24376 & 1508(6 \cdot 2)\end{array}\right\}\right)$

${ }^{\star} \mathrm{p}<0.05 .{ }^{\star \star \star} \mathrm{p}<0.001$.

TABLE II-Use of emergency orders in three types of hospital

\begin{tabular}{|c|c|c|c|}
\hline & $\begin{array}{c}\begin{array}{c}\text { No of } \\
\text { discharges }\end{array} \\
\end{array}$ & $\begin{array}{c}\text { No }(\%) \text { of } \\
\text { emergency orders }\end{array}$ & $\chi^{2}$ \\
\hline $\begin{array}{l}\text { University units: } \\
\text { 1980-1 } \\
1984-5\end{array}$ & $\begin{array}{l}4153 \\
3894\end{array}$ & $\left.\begin{array}{l}62(1 \cdot 5) \\
56(1.4)\end{array}\right\}$ & 0.01 \\
\hline $\begin{array}{l}\text { Psychiatric hospitals: } \\
1980-1 \\
1984-5\end{array}$ & $\begin{array}{l}5159 \\
6555\end{array}$ & $\left.\begin{array}{l}304(5 \cdot 9) \\
137(2 \cdot 1)\end{array}\right\}$ & $114 \cdot 7 \star \star \star \star$ \\
\hline $\begin{array}{l}\text { District general hospitals: } \\
1980-1 \\
1984-5 \\
\end{array}$ & $\begin{array}{l}11365 \\
13927\end{array}$ & $\left.\begin{array}{l}305(2 \cdot 7) \\
190(1 \cdot 4)\end{array}\right\}$ & $17 \cdot 36^{\star \star \star \star}$ \\
\hline
\end{tabular}

$\star \star \star \mathrm{p}<0.001$.

TABLE III-Use of observation orders in three types of hospital

\begin{tabular}{|c|c|c|c|}
\hline & $\begin{array}{c}\text { No of } \\
\text { discharges }\end{array}$ & $\begin{array}{c}\text { No }(\%) \text { of } \\
\text { observation orders }\end{array}$ & $\chi^{2}$ \\
\hline $\begin{array}{l}\text { University units: } \\
1980-1 \\
1984-5\end{array}$ & $\begin{array}{l}4153 \\
3894\end{array}$ & $\left.\begin{array}{l}273(6 \cdot 6) \\
226(5 \cdot 8)\end{array}\right\}$ & 1.91 \\
\hline $\begin{array}{l}\text { Psychiatric hospitals: } \\
1980-1 \\
1984-5\end{array}$ & $\begin{array}{l}5159 \\
6555\end{array}$ & $\left.\begin{array}{l}399(7 \cdot 7) \\
418(6 \cdot 3)\end{array}\right\}$ & $7 \cdot 99 \star \star \star \star$ \\
\hline $\begin{array}{l}\text { District general hospitals: } \\
1980-1 \\
1984-5\end{array}$ & $\begin{array}{l}11365 \\
13925\end{array}$ & $\left.\begin{array}{l}727(6 \cdot 4) \\
864(6 \cdot 2)\end{array}\right\}$ & 0.36 \\
\hline
\end{tabular}

Statistics were collected to permit comparison of two year periods under the 1959 act (1980 and 1981) and under the 1983 act (1984 and 1985). Medical records of all patients compulsorily admitted were examined, statistics on electroconvulsive therapy recorded, and lists for electroconvulsive therapy inspected to establish how many detained patients had received the treatment. (As three hospitals had destroyed their diaries for electroconvulsive therapy they had to be omitted from this section of our study.)

We recorded mental health review tribunal hearings along with their outcomes and the number of section 2 patients exercising this right of appeal. We also recorded the number of visits of a Mental Health Commission doctor to give a second opinion for treatment in 1984-5.

Statistics from the mental health inquiry give the total numbers of discharges for each hospital in the time periods studied so that comparisons of detention rates could be made between hospitals.

Between the time periods of the study catchment areas altered, resulting in two hospital wards being transferred from an old psychiatric hospital to a university unit. This was dealt with by including the patients in the psychiatric hospital statistics throughout. Where this might have affected the results this has been indicated.

\section{Results}

The 13 hospitals in the study included a wide variety of types, ranging from large old psychiatric hospitals with discharge rates of over 3500 patients a year to a small unit in a converted house with a discharge rate of 200 a year; 43939 discharges were studied.

In each period $15 \%$ of all patients discharged from psychiatric beds had been compulsorily detained at some time during their admission. Thus there was no difference in the overall detention rate. Major changes emerged, however, when the frequency of use of the different sections was examined. 
Table I shows a decrease in the use of emergency orders (sections 29 and 4 ) and an increase in treatment orders (sections 26 and 3) and detention order (sections 30 and 5.2). The proportion of observation orders (sections 25 and 2) remained relatively constant. The number of patients admitted on an order-that is, excluding those later detained under section 5.2-fel significantly from $11 \cdot 8 \%$ to $10 \cdot 7 \%$. This was compensated for by an increase in the number of patients detained under section 5.2.

There were 10 admissions under the police initiated section 136 in 1980-1 and 47 in $1984-5$. This is a rise from $0.05 \%$ to $0.2 \%$ of all discharges.

Tables II to $\mathrm{V}$ show the main findings when the three types of unit are compared. The breakdown of these detentions into the different sections show what is happening in more detail, but overall the number of compulsory admissions to the large psychiatric hospitals declined significantly from $16.4 \%$ to $11 \cdot 7 \%\left(\chi^{2}=54 \cdot 4 ; p<0.001\right)$. Figures for other types of unit remained unchanged.

Table II shows a decrease in use of emergency orders in the psychiatric hospitals and district general hospitals. The university units maintained

TABLE IV-Use of treatment orders in three types of hospital

\begin{tabular}{|c|c|c|c|}
\hline & $\begin{array}{c}\text { No of } \\
\text { discharges }\end{array}$ & $\begin{array}{c}\text { No }(\%) \text { of } \\
\text { treatment orders }\end{array}$ & \\
\hline $\begin{array}{l}\text { University units: } \\
1980-1 \\
1984-5\end{array}$ & $\begin{array}{l}4153 \\
3894\end{array}$ & $\left.\begin{array}{r}95(2 \cdot 3) \\
142(3 \cdot 6)\end{array}\right\}$ & $12 \cdot 51^{\star \star \star}$ \\
\hline $\begin{array}{l}\text { Psychiatric hospitals: } \\
1980-1 \\
1984-5\end{array}$ & $\begin{array}{l}5159 \\
6555\end{array}$ & $\left.\begin{array}{l}144(2 \cdot 8) \\
210(3 \cdot 2)\end{array}\right\}$ & 1.53 \\
\hline $\begin{array}{l}\text { District general hospitals: } \\
1980-1 \\
1984-5\end{array}$ & $\begin{array}{l}11365 \\
13927 \\
\end{array}$ & $\left.\begin{array}{l}124(1 \cdot 1) \\
369(2 \cdot 6)\end{array}\right\}$ & $78 \cdot 71^{\star \star \star}$ \\
\hline
\end{tabular}

TABLE V-Use of detention orders (sections 30 and 5.2) in three types of hospital

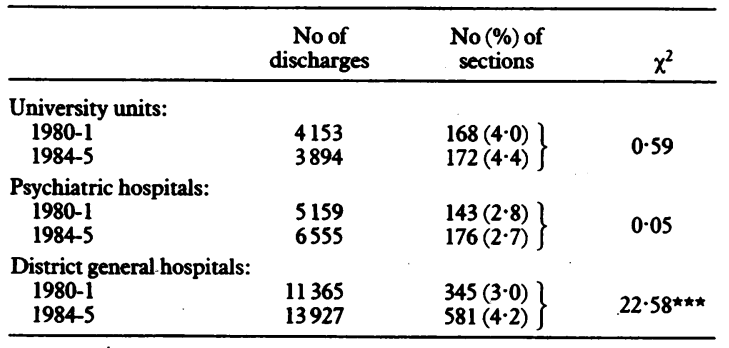

$\star \star \star \mathrm{p}<0.001$.

TABLE VI-Outcome of nurses' holding power (section 5.4)

\begin{tabular}{lcc}
\hline Outcome & $\begin{array}{c}\text { No } \\
(\mathrm{n}=35)\end{array}$ & $\begin{array}{c}\% \text { Of } \\
\text { total }\end{array}$ \\
\hline Converted to section 3 (treatment order) & 2 & 6 \\
Converted to section 2 (observation order) & 12 & 34 \\
Reverted to informal inpatients & 19 & 54 \\
Discharged on expiry of section 5.4 & 2 & 6 \\
\hline
\end{tabular}

TABLE VII-Outcome of tribunals in three types of hospital

\begin{tabular}{|c|c|c|c|c|c|}
\hline & \multicolumn{2}{|c|}{ Section 3} & \multicolumn{2}{|c|}{ Section 2} & \multirow[b]{2}{*}{$\begin{array}{c}\text { Total No o } \\
\text { tribunals }\end{array}$} \\
\hline & $\begin{array}{c}\text { No of } \\
\text { tribunals }\end{array}$ & $\begin{array}{c}\text { No of } \\
\text { discharges }\end{array}$ & $\begin{array}{c}\text { No of } \\
\text { tribunals }\end{array}$ & $\begin{array}{c}\text { No of } \\
\text { discharges }\end{array}$ & \\
\hline \multicolumn{6}{|c|}{ University units: } \\
\hline $1980-1$ & 2 & & & & 2 \\
\hline $\begin{array}{c}1984-5 \\
\text { Psychiatric }\end{array}$ & 43 & & 44 & & 87 \\
\hline \multicolumn{6}{|c|}{ Psychiatric hospitals: } \\
\hline $\begin{array}{l}1980-1 \\
1984-5\end{array}$ & 19 & 3 & & & 19 \\
\hline \multicolumn{6}{|c|}{ District general hospitals: } \\
\hline $1980-1$ & 2 & & & & 2 \\
\hline $1984-5$ & 24 & 7 & 32 & 1 & 56 \\
\hline
\end{tabular}

their previous low level of use. In general the different types of unit became more similar in their use of compulsory orders under the 1983 act than they had been before.

Table III shows a decrease in the use of observation orders in the psychiatric hospitals but not in the university units or district general hospitals, where the proportion of these orders used did not change. Some of this may be explained by the decrease in emergency orders, which would previously have been converted to observation orders.

Table IV shows an increase in the use of treatment orders in university units and district general hospitals but no change in the psychiatric hospitals.

Table $\mathrm{V}$ shows the use of orders to detain patients already in hospital. There was a substantial increase in the use of this power in the district general hospitals but not in the other types of unit.

Table VI gives the outcome of the 35 instances of the use of section 5.4 (the nurses' holding power) recorded in Greater Manchester in 1984-5.

Only $0.15 \%$ of all patients discharged in 1984 and 1985 were detained under the nurses' holding power. Although many of the patients were subsequently detained on an observation order, half of them reverted to informal status and remained in hospital voluntarily. It was uncommon for them to be either discharged home directly from the section 5.4 detention or detained on a treatment order.

In 1980-1 there were 23 mental health review tribunal hearings, which resulted in three recommendations for discharge from treatment orders. In 1984 and 1985 there were 183 such tribunal hearings. Of these, 112 were for section 2 patients, which resulted in 12 recommendations for discharge, and 69 were for section 3 patients, which led to three discharges.

Table VII shows that few hearings resulted in discharge by tribunals both before and after the 1983 act. Individual hospitals showed a wide variation in their rate of patients' appeal to tribunals. One hospital accounted for $16 \%$ of all discharges in Greater Manchester but for $43 \%$ of all tribunal hearings in this area in 1984-5. This hospital had one recommendation for discharge out of 78 tribunal hearings. The greatest increase in tribunal hearings was found in the university units, where $30 \%$ of section 3 patients appealed in 1984-5, compared with $6 \%$ and $7 \%$ in the psychiatric hospitals and district general hospitals.

In 1984-5 there were 150 second opinions given by Mental Health Act Commission doctors. Sixty were for drug treatment beyond three months' duration and 90 for electroconvulsive therapy. Of the second opinions for electroconvulsive therapy, 62 were given because the patient did not consent and 28 because the patient was incapable of understanding the nature of the treatment. There was no recorded instance of a commission doctor disagreeing with the consultant in charge. The rate of requests for second opinions varied widely between hospitals. Three hospitals with discharge rates of over 1000 patients a year did not request any second opinions in the two years studied, whereas one hospital with over 3500 discharges a year-that is, $16 \%$ of the total discharges-requested $36 \%$ of all the second opinions.

Seven per cent of all patients (both compulsory and voluntary) discharged during each of the periods studied received a course of electroconvulsive therapy during their stay. Thus there was no overall change in treatment rate. The proportion of these courses of treatment that were given to detained patients also remained constant at about $12 \%$. The proportion of courses of electroconvulsive therapy that were given after a second opinion was $6 \%$ for university units, $12 \%$ for psychiatric hospitals, and $4 \%$ for district general hospitals.

\section{Discussion}

This study of 6637 compulsory admissions gives a clear indication of some important changes since the 1983 act came into force. The reduction in use of the emergency order was one aim of the act that has been achieved. As might be expected the large psychiatric hospitals, with the greatest use of emergency orders under the 1959 act, showed the largest drop in use while the university hospitals with a previous low level of use remained unchanged. Total admissions to hospital showed no reduction corresponding to the reduced rate of emergency orders. This indicates that patients who might have been admitted on emergency orders under the 1959 act are still being treated, though either informally or on alternative orders. Admissions to psychiatric hospitals decreased while those to the other types of unit remained constant. This is not a transient effect but is borne out by inspection of the 1986 figures, which confirm the finding. Before 1983 the psychiatric hospitals had a relatively large number of compulsory admissions, but they have now come to resemble the other types of unit. We surmise that under the 1959 act the requirements for detention were more loosely 
interpreted in the psychiatric hospitals than is now allowed under the stricter specifications of the 1983 act.

The frequency of use of the 28 day observation order has remained relatively constant, contrary to the prediction that this section would be avoided by psychiatrists faced with the possibility of an early tribunal hearing. ${ }^{1}$ The new provision for enforcing treatment under this section might have made it useful on more occasions. The change in catchment area shifted an inner city population with a high rate of compulsory admission from the care of an old psychiatric hospital to a university unit. Without correction for this there would have been a false rise in detention rates in the university units and a corresponding fall in rates in the psychiatric hospitals.

The use of the six month treatment order has increased compared with its 12 month equivalent under the 1959 act. This can be explained partly by the need to renew the detention of some patients after six months rather than one year, leading to an apparent increase in the total numbers of detention orders with no corresponding increase in the number of patients detained. But this happened infrequently. Another possible reason is that if a voluntary patient was not fit to give valid consent for electroconvulsive therapy under the 1959 act consultants would sometimes go ahead with the treatment, provided that the patient's relatives consented. Under the 1983 act section 3 is usually used and a second opinion must be obtained.

The increase in the detention of patients already in hospital might be partly due to increased efforts to persuade unwilling patients to accept voluntary admission now that emergency orders are more difficult to use. In some cases these patients change their minds about accepting treatment once admitted, and a section 5.2 order would then be used to detain them. This is most evident in the district general hospitals, where the number of patients detained under section 5.2 has shown the largest rise.

The police initiated section 136 is used infrequently in Manchester compared with other regions. ${ }^{12}$ The hospital administrators in this study believed that this is due more to custom and habit than to a deliberate policy. Although there has been a rise, which we cannot explain, in the number of patients admitted in this way, it still remains a small proportion of compulsory admissions in this region.

The infrequent use of the nurses' holding power shown in this study indicates that nurses' difficulties under the 1959 act, when they were unsure of their legal right to prevent patients leaving hospital in an emergency, may have been more perceived than actual. The infrequent use of this power indicates that in Manchester there are few circumstances where a doctor cannot be contacted in time to assess the patient, though this clearly depends on the arrangements for 24 hour medical cover.

\section{TELLING PATIENTS THEIR RIGHTS}

The predicted fivefold increase in numbers of tribunal hearings has been exceeded in Manchester. The increase has been eightfold, though individual hospitals vary in the proportions of detained patients who appeal. There are certainly differences in how the hospitals carry out their duty to inform detained patients of their rights. University units had a huge excess of tribunal hearings compared with the other hospitals. In the largest university unit an administrator had the task of formally delivering and explaining the leaflet setting out the patient's rights and inquiring whether the patient wanted to appeal. In other hospitals this task was delegated to the nurse in charge. Although a formal record was made that the patient had received and understood the leaflet, our observations were that each ward and each nurse had different ideas about how it should be done and there were wide variations in the quality of explanation received by the patient. Giving clear information substantially increases the rate of uptake of the right of appeal. Paradoxically, the administrators who discharge their responsibility to provide information most conscientiously create a great deal of extra administrative work for themselves and their staff. This is particularly evident in the case of patients who appeal and subsequently change their minds before the arranged tribunal hearing.

Despite the large increase in numbers of tribunals the proportion of detained patients who are discharged by a tribunal has not changed. This suggests that there were probably few abuses of the observation order. This confirms the fears previously expressed by hospital administrators that the new right of appeal for section 2 patients would cause their staff much extra work to little effect. It is, however, impossible to quantify the extra sense of justice the detained patient might feel at having his case heard by an independent tribunal, even if he is not discharged.

In Greater Manchester the new regulations governing consent for electroconvulsive therapy have not affected the overall treatment rates or the number of detained patients receiving courses of electroconvulsive therapy. It seems that patients who need this treatment will receive it under the 1983 act as they did before. The predictions of disputes caused by Mental Health Act Commission doctors disagreeing with the consultant when giving second opinions for electroconvulsive therapy have not materialised. We found no instance of this occurring. Individual hospitals varied widely in their numbers of requests for second opinions for both electroconvulsive therapy and long term drug treatment. As it is unlikely that patients from different catchment areas vary widely in their willingness to accept or their capacity to consent to compulsory treatment this must reflect differences in clinical practice.

The main effect of the Mental Health Act 1983 in the Manchester area has been to reduce the use of emergency orders in hospitals that previously used them frequently. It has not affected the use of observation orders, and the nurses' holding power is used infrequently. Many patients are taking advantage of the new right of appeal, but relatively few are discharged by tribunal, and many of the predicted pitfalls of the new act have not occurred in practice.

We thank the administrators and the records staff of the hospitals included in the study, which was supported by a generous grant from the Nuffield Provincial Hospitals Trust.

\section{References}

1 Szmukler G. The Mental Health (Amendment) Act 1982: will it make a difference? Bulletin of the Royal College of Psychiarists 1983;7:158-60.

2 Paterson HF, Dabbs AR. Section 29. Br f Psychiatry 1963;109:202-5.

2 Paterson HF, Dabbs AR. Section 29. Brf Psychiatry 1963;109:202-5.

3 Enoch MD, Barker JC. Misuse of section 29: fact or fiction? Lancet 1965;i:760-1.
4 Chiswick D. Section 31 of the Mental Health (Scotland) Act 1960. Compulsory crisis intervention? Int f Law Psychiatry 1980;3:435-41.

5 Haslam MT. Mental Health Act and consent to electroplexy. Br Med f 1978;ii: 1083.

6 Morrison RM. "Approved" social worker. $\mathcal{F}$ R Soc Health 1979;99:216-8.

7 Beedie MA, Bluglass R. Consent to psychiatric treatment: practical implications of the Mental Health (Amendment) Bill. BrMed $\mathcal{F}$ 1982;284:1613-6.

8 Farmer A. Tribunal nouveau 1983: a first taste of the Mental Health Act. Bulletin of the Royal College of Psychiatrists 1984;8:23-4.

9 Fenton TW. The aftermath of the Mental Health Act 1983: some preliminary impressions. Bulletin of the Royal College of Psychiatrists 1984;8:190-3.

10 Winterson MJ, Barraclough BM. Effects of 1983 Mental Health Act. Lancet 1985;ii: 1426.

11 Winterson MJ, Barraclough BM. Effects of 1983 mental health legislation on compulsory admissions to a district general hospital. Lancet 1984;ii:44.

12 Szmukler GI, Bird AS, Button EJ. Compulsory admissions in a London borough. I. Social and clinical features and a follow-up. Psychological Medicine 1981;11:617-36. 